\title{
Stemness Is Only a State of the Cell
}

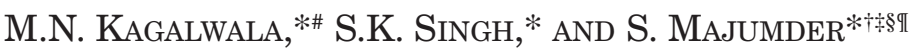 \\ *Department of Genetics, ${ }^{\dagger}$ Department of Neuro-Oncology, ${ }^{*}$ The Brain Tumor Center, ${ }^{\circledR}$ Center for Stem Cell \\ and Developmental Biology, The University of Texas M.D. Anderson Cancer Center, Houston, Texas 77030; \\ "Program in Genes and Development, The University of Texas Graduate School of Biomedical Sciences \\ at Houston, Houston, Texas 77030
}

\begin{abstract}
How the programming and reprogramming of stem/progenitor cells regulate normal cell development and cancer is still not well known. One of the tools that we have chosen to use to investigate stem cell regulation is the transcriptional repressor element 1-silencing transcription factor (REST). REST contains a DNA-binding domain and two repressor domains. Once bound to its target genes, REST can interact with several cellular corepressors to regulate epigenetic modifications. REST is expressed in most nonneural cells, including neural stem/progenitor cells (NSCs), but it is absent in most neuronal cells. REST was originally found to be a major transcriptional repressor of neural differentiation. Previously, we found that activation of REST target genes in NSCs was sufficient to cause neuronal differentiation. Furthermore, the activation of REST target genes in myoblasts was sufficient to override the muscle differentiation pathway and produce a physiologically active neuronal phenotype. Although REST is normally not expressed in most neural cells, we previously found that approximately $50 \%$ of human medulloblastomas, a malignant pediatric brain tumor, express REST and that abnormal expression of REST in NSCs causes medulloblastoma-like cerebellar tumors by blocking neuronal differentiation. Interestingly, REST is also expressed at high levels in mouse embryonic stem (mES) cells, but its role in these cells is not understood. Recently, we found that REST maintains self-renewal and pluripotency in mES cells through suppression of microRNA-21 (miRNA21). Thus, REST is a newly discovered element of the interconnected regulatory network that maintains the self-renewal and pluripotency of mES cells. Taken together, the results of several different studies indicate that stem/progenitor cells are more flexible than previously believed and that a simple alteration of transcriptional regulators in these cells can affect both normal cell development and cancer.
\end{abstract}

REST has been the focus of research in many laboratories since its discovery (Chong et al. 1995; Schoenherr and Anderson 1995), and our understanding of its regulation and roles has improved considerably. Initial studies concluded that REST was a transcriptional repressor of a group of genes primarily involved in terminal neuronal differentiation. In accordance with these findings, the REST expression pattern was shown to be present mainly in nonneuronal cells and rarely in neurons, with few exceptions (Koenigsberger et al. 2000; Griffith et al. 2001; Shimojo and Hersh 2004). REST was also found to regulate neurogenesis via miRNA-124a (miR-124a) (Conaco et al. 2006). These authors found that REST and miR-124a are expressed in a reciprocal manner and that miR-124a is a direct target of REST. It was no coincidence that many of the targets of miR-124a were shown to be nonneuronal transcripts that assist REST in efficient neuronal differentiation. Since that first report, the list of miRNAs that are predicted to be or are regulated by REST has increased (Wu and Xie 2006; Otto et al. 2007). Many outstanding reviews about REST regulation and its proposed functions have been written in recent years (Ballas and Mandel 2005; Coulson 2005; Hsieh and Gage 2005; Lunyak and Rosenfeld 2005; Cao et al. 2006; Majumder 2006; Weissman 2008). Here, we briefly describe the critical aspects of REST biology and the con-

\#Present address: Laboratory of Genetics, Salk Institute for Biological Studies, La Jolla, California 92037. tributions to our understanding of REST from work done in our laboratory.

\section{REST IN ACTION Same Lyrics}

REST is a zinc finger protein (1097 amino acids long) with a DNA-binding domain sandwiched between two repressor domains, RD1 and RD2, on its amino terminus and carboxyl terminus, respectively (Ballas and Mandel 2005; Coulson 2005; Hsieh and Gage 2005; Lunyak and Rosenfeld 2005; Cao et al. 2006). A 21-23-bp DNA element known as RE-1 was shown to be necessary and sufficient for the recruitment of REST to specific gene loci, and about 2000 such elements are predicted to be present throughout the mammalian genome (Bruce et al. 2004). Recently, a novel bipartite REST-binding element was discovered (Johnson et al. 2007).

\section{Different Rhythm, Different Melody}

REST interacts with several cellular cofactors through its two repressor domains and brings about direct transcriptional repression or alters the chromatin to a repressed state (Ballas and Mandel 2005; Coulson 2005; Hsieh and Gage 2005; Lunyak and Rosenfeld 2005; Cao et al. 2006). The interactors of the RD1 domain include $\mathrm{mSin} 3 \mathrm{~A}$, the histone deacetylase (HDAC) complex, and N-CoR; the RD2 domain interactors include CoREST, the mSin3A/HDAC 
complex, histone H3-K9 methyltransferase G9a, and histone H3-K4 demethylase LSD1. Depending on the context, the REST complex can also function in conjunction with, for example, DNA methyltransferase 1, DNA-methylCpG-binding protein-2, the chromatin-remodeling complex, and SWI/SNF. In protein-protein interaction studies, REST has also been shown to interact with the TATA-box binding protein and small RNA polymerase II carboxyl-terminal domain phosphatases.

\section{Different Music}

Although REST is largely regarded as a repressor molecule in certain cells such as neural stem cells, the presence of double-stranded RNA molecules with RE-1-like sequences can modulate its function and turn it into an activator molecule (Kuwabara et al. 2004). Various isoforms (e.g., REST4) have been shown to act as dominantnegative molecules in REST function and compete with its interacting partner RILP (a LIM domain protein) for cellular localization (Shimojo et al. 1999; Shimojo and Hersh 2004). The REST gene was found to be transcriptionally activated by Wnt signaling in human embryonic carcinoma cells (Willert et al. 2002) and directly in the chick spinal cord (Nishihara et al. 2003). In contrast, REST gene transcription can be blocked by the binding of the unliganded retinoic acid receptor-repressor complex to the retinoic acid receptor element found on the REST gene promoter (Lunyak et al. 2002; Ballas et al. 2005).

Besides having a critical role in neurogenesis, REST has been found to regulate several genes that may affect important biological processes. For example, ischemic insults were found to derepress REST mRNA and protein in dying neurons, and this was suggested to be a critical mechanism in insult-induced neuronal death (Calderone et al. 2003). REST and huntingtin protein were found to form a complex that forced REST to localize in the cytoplasm in normal neuronal cells. In patients with Huntington's disease, this interaction was ablated by the huntington mutation, resulting in the translocation of REST to the nucleus and causing a blockade of the expression of neuronal genes such as BDNF (brain-derived neurotrophic factor) (Zuccato et al. 2003, 2007), suggesting that REST has a role in Huntington's disease. REST was found to repress the $\mu$-opioid receptor in neuronal cells and thus may have a role in opium addiction (Kim et al. 2004; Formisano et al. 2007). REST was found to repress the serotonin 1A receptor, which is implicated in depression and anxiety (Lemonde et al. 2004). REST also may have a role in other mental disorders, such as X-linked mental retardation (Tahiliani et al. 2007; Ding et al. 2008) and Down syndrome (Canzonetta et al. 2008).

Among nonneuronal tissues, REST was found to be present in normal ventricular myocytes and to suppress the expression of multiple fetal cardiac genes (Kuwahara et al. 2003). In cardiac dysfunction and arrhythmogenesis, REST expression was inhibited, resulting in the expression of fetal cardiac genes. These results suggest that REST has a role in maintaining normal cardiac structure and function and that its deregulation may cause cardiac dysfunction (Bingham et al. 2007). REST was found to be expressed in vascular smooth muscle cells, where it suppressed the expression of a critical potassium channel gene and, thereby, regulated both normal and diseased states of the cell (Cheong et al. 2005).

REST shows both tumor suppressor and oncogenic effects, depending on the cellular context (Coulson 2005; Majumder 2006). The epithelial cells of tissues such as those of the lung, breast, and colon normally express REST and suppress expression of neuronal genes. In this context, REST functions as a tumor suppressor, and the abnormal lack of REST activity in these cells may lead to oncogenesis. In contrast, differentiating or differentiated neuronal cells generally do not express REST and do express neuronal genes. In this context, the suppressive activity of REST may have an oncogenic function. Proteasomal degradation is a major mechanism regulating the REST protein and, thereby, REST activity (Ballas et al. 2005; Westbrook et al. 2005, 2008; Guardavaccaro et al. 2008). It was found that the carboxyl terminus of the REST protein interacts with the F-box protein $\beta$-TrCP and is degraded in a ubiquitin ligase SCF- $\beta$-TrCP-dependent manner. Proteasomal degradation is critical during neuronal differentiation (Ballas et al. 2005; Westbrook et al. 2008). In addition, $\beta$-TrCP overexpression may cause oncogenic transformation of human mammary epithelial cells via REST degradation, which is consistent with the function of REST as a tumor suppressor (Westbrook et al. 2005, 2008; Weissman 2008). On the other hand, degradation of REST protein $\beta$-TrCP during the $\mathrm{G}_{2}$ phase of the cell cycle has been shown to cause transcriptional activation of the REST target gene Mad2, an essential component required for proper mitotic spindle assembly. Thus, a REST mutant defective in binding to $\beta$-TrCP was unable to activate the spindle checkpoint and demonstrated various mitotic defects. These results suggest that high levels of unchecked REST could have a role in promoting genomic instability, thus resulting in the oncogenic function of REST. Previous studies from our laboratory and others have shown that REST misexpression or overexpression in neural cells causes medulloblastomas (see below). It would be worth investigating whether this process involves genomic instability.

Depending on the cellular context, the relative abundance of its interacting partners, and the specific interactions, a variety of combinatorial mechanisms can thus be used by REST to differentially influence the transcription of each of its many target genes (Andres et al. 1999; Jepsen et al. 2000; Ballas et al. 2001; Lunyak et al. 2002). Furthermore, the epigenetic marks caused by the RESTcosuppressor complex on its target genes were found to differ in differentiated fibroblasts, pluripotent embryonic stem (ES) cells, neural progenitors, mature neurons derived from ES cells, and mature neurons from the adult brain (Ballas and Mandel 2005; Hsieh and Gage 2005).

\section{FLEXIBILITY OF NEURAL STEM/PROGENITOR CELLS: NEURONAL DIFFERENTIATION}

In early embryogenesis (stages E11.5-E13.5), REST is expressed in most nonneuronal cells (Chong et al. 1995). Studies with $\mathrm{REST}^{-/}$mice suggested that although REST is 
required for the suppression of its target genes, activation of many of its targets was not solely dependent on the absence of the REST protein (Chen et al. 1998), and lack of REST alone did not activate these REST target genes. Our work suggested that, depending on the requirements for their activation, REST target genes can be broadly categorized into two groups. The first group is suppressed in the presence of REST but is transcriptionally active when RESTmediated repression is absent (e.g., $\beta$-tubulin III gene); the second group of target genes is also suppressed by REST but require additional promoter/enhancer-specific activators/events apart from the absence of REST-mediated repression for their activation (e.g., synapsin and glutamate receptor genes) (Immaneni et al. 2000).

Mandel's group used the staged conversion of ES cells into neural stem cells (NSCs) and further differentiated the NSCs into mature neurons in the presence of retinoic acid (Ballas et al. 2005). Their work provided a mechanistic basis for the two classes of REST target genes. They found that REST and its cosuppressor complex use two distinct mechanisms to regulate the target genes. In the first mechanism, the RE-1 site of the promoter is occupied by the REST-cosuppressor complex, which suppresses chromatin expression such that the removal of REST from the chromatin results in the expression of class I neuronal genes. In the second mechanism, the REST-cosuppressor complex occupies the RE-1 site of the promoter; in addition, CoREST/HDAC and methyl-CpG-binding protein2/mSin3/HDAC complexes occupy distinct but adjacent methylated $\mathrm{CpG}$ sites. In this scenario, removal of REST from the chromatin alone does not activate these genes (class II neuronal genes) because of the additional suppressor complexes located on the methylated $\mathrm{CpG}$ sites. However, the class II genes can be activated upon application of a specific stimulus, such as membrane depolarization, which relieves the additional chromatin suppression and provides neuronal plasticity. These findings were validated in cortical progenitors and cortical neurons isolated from mouse embryos.

To determine the impact of REST-mediated suppression on neuronal differentiation, we examined what happens when we force the REST target genes to be activated. For this purpose, we constructed a recombinant transcription factor, REST-VP16, in which both suppressor domains of REST were replaced with the strong activation domain of the herpes simplex virus protein VP16 (Immaneni et al. 2000; Lawinger et al. 2000; Watanabe et al. 2004; Su et al. 2006). We found that REST-VP16 binds to the same DNAbinding site as does REST, competes with REST for DNA binding, and activates its target genes even in the presence of REST in multiple cell types (Immaneni et al. 2000). When we expressed REST-VP16 in an NSC line generated from newborn mouse cerebellum, it rapidly converted the cells into a mature neuronal phenotype that included neurite outgrowth, expression of multiple neuronal genes (both target and nontarget REST genes), survival in the presence of mitotic inhibitors, and synaptic vesicle recycling and glutamate-induced calcium influx ( $\mathrm{Su}$ et al. 2004). Such expeditious differentiation was not seen in NSCs that did not express REST-VP16. These results showed that direct activation of REST target genes in
NSCs is sufficient to cause rapid neuronal differentiation and indicated that these cells are more flexible than previously thought.

\section{FLEXIBILITY OF MUSCLE PROGENITOR CELLS: NEURONAL DIFFERENTIATION}

To examine the cellular flexibility of nonneuronal stem/progenitor cells, we expressed REST-VP16 in muscle progenitor cells (myoblasts) (Watanabe et al. 2004). These cells were not thought to be capable of converting to a neuronal phenotype. Surprisingly, our results showed that the expression of REST-VP16 in myoblasts grown under muscle differentiation conditions blocked entry into the muscle differentiation pathway, countered endogenous REST-dependent suppression, activated the REST target genes, and, surprisingly, activated other neuronal differentiation genes and converted the myoblasts into a physiologically active neuronal phenotype. Furthermore, these in-vitro-differentiated neuronal cells, when injected into the mouse brain, survived, incorporated into the normal brain, and did not form tumors.

Our further unpublished results indicated that when the myoblast-derived neuronal cells were transplanted into the cerebella of newborn mice, the cells integrated into the cerebellar environment, did not form tumors, exhibited neuronal properties, including action potential, and were capable of receiving glutamatergic synaptic input. This was the first study showing myoblasts being converted into a neuronal phenotype, which indicated a high degree of flexibility in terms of the cellular fate of these cells. This enormous cellular flexibility has been further demonstrated in recent studies by other investigators, indicating that mouse and human fibroblasts can be reprogrammed to an induced-pluripotent state by the transfer of a set of four transcription factors (Jaenisch and Young 2008; Lengner et al. 2008; Yamanaka 2008; Yu and Thomson 2008; ).

\section{FLEXIBILITY OF NEURAL STEM/PROGENITOR CELLS: MEDULLOBLASTOMA}

Medulloblastoma is one of the most malignant brain tumors in children and is believed to arise from undifferentiated NSCs present in the cerebellum. Pathways involved in normal early development of the brain (such as Hedgehog and Wnt signaling) are implicated in medulloblastoma tumorigenesis (McMahon 2000; Eberhart and Burger 2003; Gilbertson 2004; Raffel 2004; Rutka et al. 2004; Fogarty et al. 2005; Romer and Curran 2005; Dellovade et al. 2006; Knoepfler and Kenney 2006). During the progression or initiation of medulloblastoma, the activities of these pathways are sustained at higher than normal levels or the pathways are abnormally activated. However, mutations activating these pathways have been documented in only a modest percentage of human medulloblastoma tumors.

We found that many human medulloblastoma samples and established human medulloblastoma cell lines had a much higher expression of REST than did neuronal cells or normal brain cells (Lawinger et al. 2000; Su et al. 2004; Fuller et al. 2005). As expected, the REST-positive human medulloblastoma tumor cells did not express REST target 
genes, such as synapsin. Our further work showed that transgenic mice expressing REST in neuronal cells appeared to develop normally, without tumor formation (S. Majumder, unpubl.), indicating that abnormal expression of REST in NSCs alone was not sufficient to cause tumorigenesis. Similarly, David Anderson's group found that neuronal cells constitutively expressing REST did not form tumors and appeared to acquire a normal neuronal morphology, except that they manifested axon pathfinding errors (Paquette et al. 2000). Reexamination of human medulloblastoma tumors indicated that many of these tumors expressed abnormally high levels of both REST and Myc (Su et al. 2006). Furthermore, NSCs engineered to overexpress activated Myc and REST, and not the control cells, gave rise to tumors in the mouse cerebellum, the site of human medulloblastoma formation. These tumors were blocked in neuronal differentiation and were morphologically similar to human medulloblastoma.

The cells that produced tumors in the cerebellum did not produce tumors in the cortex, indicating the critical role of the local brain environment in the formation of tumors $(\mathrm{Su}$ et al. 2006). Such site-specific tumor growth suggests the role of a niche where REST-MYC-driven tumors can originate. Thus, efficient medulloblastoma tumorigenesis occurs when NSCs are present in an appropriate environment/niche and are forced to express both Myc, causing overall increased proliferation, and REST, the suppressor function of which causes the blockade of differentiation (maintenance of "stemness"). We further found that countering the effects of REST with REST-VP16 in Myc- and REST-expressing NSCs counteracted the tumorigenic potential of the cells, in a manner similar to that observed in human medulloblastoma cell lines, indicating that REST has a critical role in medulloblastoma tumorigenesis.

The oncogenic role of the overexpression/misexpression of REST in neuronal cells is further supported by studies from other laboratories that found REST overexpression in several neuroblastoma cells, with concomitant suppression of neuronal differentiation genes (Nishimura et al. 1996; Higashino et al. 2003). Furthermore, when neuroblastoma cells were forced to differentiate, REST expression decreased and neuronal markers increased in these cells. Taken together, these results suggested that the abnormal maintenance of stemness and the resulting blockade of differentiation in combination with increased proliferation in NSCs causing a state of restricted cellular flexibility can impart oncogenic properties.

\section{FLEXIBILITY OF ES CELLS: SELF-RENEWAL VERSUS DIFFERENTIATION}

ES cells are pluripotent cells that show extreme cellular flexibility and have the potential for both indefinite selfrenewal and differentiation into all three germ layers of the body (Pan and Thomson 2007). These properties of ES cells are regulated by a combination of core regulatory factors, such as Oct4, Sox2, Nanog, and Klf4 and Lin28 (Jaenisch and Young 2008; Yamanaka 2008; Yu and Thomson 2008). REST was found to be expressed at high levels in mouse ES (mES) cells (Ballas and Mandel 2005), but its role in these cells was not understood. By perform- ing chromatin immunoprecipitation (ChIP)-on-Chip assays, researchers showed that Oct4, Sox2, and Nanog cooccupy the REST gene, suggesting that REST is in the expanded regulatory circuit that controls self-renewal and pluripotency in ES cells (Boyer et al. 2005). Indeed, we found that REST maintains self-renewal and pluripotency in $\mathrm{mES}$ cells through suppression of miR-21 (Singh et al. 2008). As with known self-renewal markers, REST expression is much higher in self-renewing mES cells than in differentiating $\mathrm{mES}(\mathrm{mEB})$ cells. The heterozygous deletion of REST $\left(\mathrm{REST}^{+-}\right)$and its small interfering RNA (siRNA)-mediated knockdown in mES cells-both of which result in significantly lower levels of REST protein - cause a loss of self-renewal, even when the cells are grown under self-renewal conditions, and lead to the expression of markers specific for multiple lineages. Conversely, exogenously added REST maintains selfrenewal in mEB cells. In addition, $R E S T^{+/-} \mathrm{mES}$ cells cultured under self-renewal conditions express substantially reduced levels of several self-renewal regulators, including Oct4, Nanog, Sox2, and c-Myc, and exogenously added REST in mEB cells maintains the self-renewal phenotypes and expression of these self-renewal regulators.

We further found that in mES cells, REST was bound to the gene chromatin of a set of miRNAs that potentially target self-renewal genes. Whereas mES cells and $\mathrm{mEB}$ cells containing exogenously added REST expressed lower levels of these miRNAs, wild-type mEB cells, $R E S T^{+/} \mathrm{mES}$ cells, and siREST-treated $\mathrm{mES}$ cells expressed higher levels of these miRNAs. At least one of these REST-regulated miRNAs, miR-21, specifically suppressed the selfrenewal of mES cells, corresponding to the decreased expression of Oct4, Nanog, Sox2, and c-Myc. Thus, REST is a newly discovered element of the interconnected regulatory network that maintains the self-renewal and pluripotency of mES cells.

Our conclusions are not yet universally accepted; two recent papers contain somewhat contradictory results. In the first, the investigators report that REST ablation does not alter ES cell pluripotency (Sun et al. 2008). In the second, Johnson et al. (2008) report that although REST indeed has a key role in the maintenance of the ES cell phenotype, REST does not bind to the miR-21 gene chromatin. Both our conventional results and the ChIP-quantitative polymerase chain reaction (qPCR) results suggested specific binding of REST to a particular site in the $m i R-21$ gene chromatin. Moreover, our data suggests that this binding is functional and REST directly regulates miR-21 expression. This was clearly demonstrated by the up-regulation of miR-21 upon depletion of REST. Unfortunately, the Johnson et al. study did not provide a REST-miR-21 functional assay. In contrast, two other recent papers support our work: Results from Stuart Orkin's laboratory (Kim et al. 2008) indicated that REST is indeed part of the network that regulates ES cell self-renewal and pluripotency, and Dean Nizetic's laboratory (Canzonetta et al. 2008) showed that mES cells with lower REST levels derived from a mouse model of Down syndrome have decreased levels of self-renewal markers and a higher propensity toward differentiation, even when cultured in the pres- 
ence of leukemia inhibitory factor (LIF). In addition, Phillip Sharp's laboratory (Houbaviy et al. 2003) found that miR-21 expression was higher in differentiated $\mathrm{mES}$ cellsthan in undifferentiated mES cells, supporting our conclusions. Thus, future work is needed to clarify these contradictory observations in terms of REST's role in maintaining self-renewal and pluripotency of mES cells.

\section{ROLE OF REST IN THE ICM OF BLASTOCYSTS}

We found that the inner cell mass (ICM) of mouse blastocysts coexpressed REST and the self-renewal markers Oct4, Sox2, and Nanog. However, the role of REST in the ICM of the developing mouse blastocyst is still unclear. $R E S T^{+/-}$haploinsufficient mice have an apparently normal phenotype (Chen et al. 1998), similar to that in mice haploinsufficient in most of the other known self-renewal factors or regulators, such as Oct4 (Nichols et al. 1998), Nanog (Mitsui et al. 2003), and Sox2 (Avilion et al. 2003), and the components of the LIF-STAT3-c-Myc pathway (LIF, Stewart et al. 1992; LIF-receptor $\beta$ [LIFR $\beta$ ], Li et al. 1995; gp130, Nichols et al. 2001; STAT3, Takeda et al. 1997; cMyc, Davis et al. 1993). All of these haploinsufficient mice were apparently normal. However, the complete loss of the individual regulators had variable effects. $R_{E S T^{-/}}$embryos could survive past the blastocyst stage but showed progressive embryonic lethality between embryonic days 9.5 and 11 , an apparent result of the lack of REST's role in regulating self-renewal and pluripotency in the ICM cell population under normal conditions (Chen et al. 1998). In comparison, Oct4 $4^{--}$, Nanog $^{--}$, and Sox $2^{-/-}$embryos developed to the blastocyst stage, but the ICM cells failed to develop normally (Nichols et al. 1998; Avilion et al. 2003; Chambers et al. 2003; Mitsui et al. 2003). In contrast, embryos deficient in the components of the LIF-STAT3 pathway showed an apparent lack of an immediate effect on the ICM cells. $L I F^{-/}$mice were viable and showed only retarded postnatal growth (Stewart et al. 1992), $L I F R \beta^{-/}$ mice died only after birth ( $\mathrm{Li}$ et al. 1995), gp130/- mice died between 12.5 days postcoitum and term (Nichols et al. 2001); STAT3 ${ }^{--}$embryos developed until embryonic day 6 and then degenerated between embryonic days 6.5 and 7.5 (Takeda et al. 1997); and c-Myc ${ }^{-/}$mice developed until embryonic day 10.5 (Davis et al. 1993). Thus, in terms of ICM development, REST ${ }^{-}$embryos are more similar to those deficient in the LIF-STAT3 pathway than to those deficient in Oct4, Nanog, and Sox2.

Although the exact nature of REST's role in the pluripotent ICM of blastocysts is still unknown, there are several possible explanations. One is that the ICM cell population under normal conditions is transient, so that even the complete absence of REST does not produce its full detrimental effect. However, if the ICM cells were capable of slowed development ("diapause"), a phenomenon that has evolved in some mammals, including mice, to get around adverse conditions during pregnancy, the deficiency of REST would result in the developmental arrest of blastocysts. This is supported by the finding that the develop-

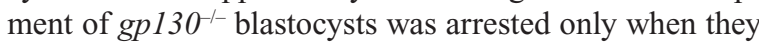
were subjected to diapause (Nichols et al. 2001).

\section{REST AS A TOOL TO UNDERSTAND CELLULAR FLEXIBILITY}

On the basis of our knowledge about REST and the mechanisms it uses to affect multiple cellular processes in different cellular contexts, we present a model of how REST may be able to accomplish all of these seemingly diverse functions (Fig. 1). The following are two crucial factors about REST: (1) It is normally expressed in multiple cell types ranging from embryonic stem cells to adult nonneuronal cells and it has an important role in each of these cell types, although expression levels vary between cell types. (2) Different cellular functions seem to be affected by REST levels/function. During early development, the key role of REST appears to be to restrict expression of lineage-specific genes and maintain selfrenewal. In ES cells, where REST is highly expressed, REST maintains self-renewal by repressing its targets, mainly the expression of miR-21 (Fig. 1). As shown by other investigators, REST protein levels must decrease if ES cells are to undergo differentiation (Ballas et al. 2005), and this decrease is mediated by cytoplasmic proteasome machinery after the REST degron is marked for degradation by $\beta-\operatorname{TrCP}$ (Ballas et al. 2005; Westbrook et al. 2008).

In the course of normal development, the gradual decrease in REST levels thus has a critical role in the controlled loss of pluripotency and yet allows some cells (such as NSCs) to retain the capacity to differentiate into more restricted cell types. It is imperative to understand whether there is an internal hierarchy among the targets of REST (based on the affinity of REST for RE-1 sites and chromatin context) and their repression is thus a function of the level of REST (and/or its cofactors). This built-in affinity sensor between REST levels and suppressed targets would allow for the cell-type-specific manifestation of REST function, including maintenance of pluripotency in ES cells and differentiation of NSCs into neurons. The microenvironments (although not completely understood) of these cells may have a critical role in controlling REST levels and other factors needed for its functions.

The Wnt and Shh signaling pathways have been shown to regulate neurogenesis (Kenney et al. 2004; Lie et al. 2005), where Wnt and Shh signaling are important for the initial expansion of NSCs, and another set of signals then allows these cells to differentiate by further repressing REST levels such that terminally differentiated neurons do not have any detectable levels of REST. Finally, in nonneuronal cells, REST levels are sufficient to suppress neuronal differentiation and prevent any misexpression of REST target genes, thus helping to maintain the cellular identity. It is also noteworthy that REST function is dependent on the levels of cofactors and on the presence of cell-specific activator(s). Thus, there are two scenarios by which altered REST function may lead to cellular abnormalities and tumorigenesis. As discussed earlier, REST functions as a tumor suppressor or oncogene in a context-dependent manner.

\section{CONCLUSIONS}

The flexibility of stem/progenitor cells is increasingly found to regulate both normal and abnormal development 
A

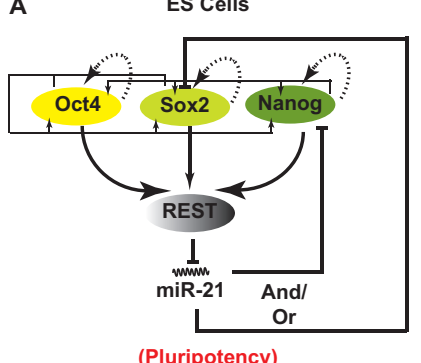

D

(Pluripotency) B Neural Stem/

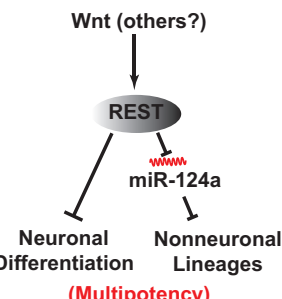

(Multipotency)
C Normal cells (nonneural)

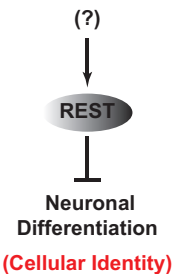

REST Levels

E

Neural Stem/Progenitor Cells (early development)

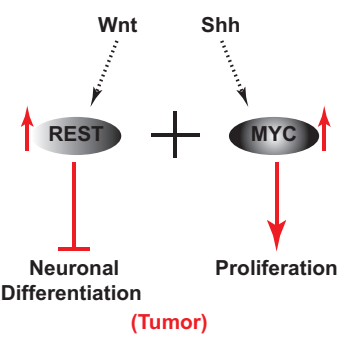

F Nonneural cells

(adult)

Dominant-

Negative

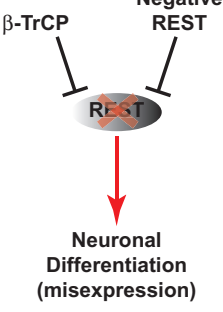

(Tumor)

Figure 1. REST-directed cellular flexibility. (A) REST maintains self-renewal and pluripotency in ES cells via miRNA-21, which in turn could potentially target Sox 2 and/or Nanog and the Oct4-Sox2-Nanog circuit. (B) REST has a critical role in blocking differentiation of neural stem/progenitor cells into neuronal lineage both by directly blocking expression of neuronal target genes and indirectly by preventing the expression of miR-124a, which destabilizes mRNAs of nonneuronal genes. (C) REST also maintains cellular identity of nonneural cells such as fibroblast cells by blocking neuronal genes. $(D)$ Level of REST protein in embryonic stem cells compared with neural stem/progenitor cells. $(E)$ Overexpression of both REST and Myc in neural stem/progenitor cells leads to tumor formation as a result of the block in neural differentiation (maintenance of "stemness") and a simultaneous increase in proliferation. $(F)$ Loss of REST in nonneural cells, in which it is normally present, causes precocious expression of neuronal genes, leading to tumor formation in a context-dependent manner.

such as cancer and other diseases. Recent discoveries have shed light on REST's role in directing some important aspects of this process. As a regulator of a large number of genes, depending on the cellular context, on the amount of REST protein present in the cell, and on the affinity of the REST protein complex toward its specific target gene in the given cellular environment, including the cell's chromatin architecture, REST is likely to modulate the flexibility of stem/progenitor cells and, thus, impact health and disease in more ways than are currently known. Most of the exciting discoveries in that respect are yet to come.

\section{ACKNOWLEDGMENTS}

We thank the National Institutes of Health for funding (grants CA97124 and CA81255 to S.M.). M.N.K. and S.K.S. were both recipients of the Dodie Hawn Fellowship in Cancer Genetics.

\section{REFERENCES}

Andres, M.E., Burger, C., Peral-Rubio, M.J., Battaglioli, E., Anderson, M.E., Grimes, J., Dallman, J., Ballas, N., and Mandel, G. 1999. CoREST: A functional corepressor required for regulation of neural-specific gene expression. Proc. Natl. Acad. Sci. 96: 9873-9878.

Avilion, A.A., Nicolis, S.K., Pevny, L.H., Perez, L., Vivian, N., and Lovell-Badge, R. 2003. Multipotent cell lineages in early mouse development depend on SOX2 function. Genes Dev. 17: $126-140$

Ballas, N. and Mandel, G. 2005. The many faces of REST oversee epigenetic programming of neuronal genes. Curr. Opin. Neurobiol. 15: 500-506.

Ballas, N., Grunseich, C., Lu, D.D., Speh, J.C., and Mandel, G. 2005. REST and its corepressors mediate plasticity of neuronal gene chromatin throughout neurogenesis. Cell 121: 645-657.

Ballas, N., Battaglioli, E., Atouf, F., Andres, M.E., Chenoweth, J., Anderson, M.E., Burger, C., Moniwa, M., Davie, J.R., Bowers, W.J., et al. 2001. Regulation of neuronal traits by a novel transcriptional complex. Neuron 31: 353-365.

Bingham, A.J., Ooi, L., Kozera, L., White, E., and Wood, I.C. 2007. The repressor element 1 -silencing transcription factor regulates heart-specific gene expression using multiple chromatin-modifying complexes. Mol. Cell. Biol. 27: 4082-4092.

Boyer, L.A., Lee, T.I., Cole, M.F., Johnstone, S.E., Levine, S.S., Zucker, J.P., Guenther, M.G., Kumar, R.M., Murray, H.L., Jenner, R.G., et al. 2005. Core transcriptional regulatory circuitry in human embryonic stem cells. Cell 122: 947-956.

Bruce, A.W., Donaldson, I.J., Wood, I.C., Yerbury, S.A., Sadowski, M.I., Chapman, M., Gottgens, B., and Buckley, N.J. 2004. Genome-wide analysis of repressor element 1 silencing transcription factor/neuron-restrictive silencing factor (REST/ NRSF) target genes. Proc. Natl. Acad. Sci. 101: 10458-10463. 
Calderone, A., Jover, T., Noh, K.M., Tanaka, H., Yokota, H., Lin, Y., Grooms, S.Y., Regis, R., Bennett, M.V., and Zukin, R.S. 2003. Ischemic insults derepress the gene silencer REST in neurons destined to die. J. Neurosci. 23: 2112-2121.

Canzonetta, C., Mulligan, C., Deutsch, S., Ruf, S., O’Doherty, A., Lyle, R., Borel, C., Lin-Marq, N., Delom, F., Groet, J., et al. 2008. DYRK1A-dosage imbalance perturbs NRSF/REST levels, deregulating pluripotency and embryonic stem cell fate in Down syndrome. Am. J. Hum. Genet. 83: 388-400.

Cao, X., Yeo, G., Muotri, A.R., Kuwabara, T., and Gage, F.H. 2006. Noncoding RNAs in the mammalian central nervous system. Annu. Rev. Neurosci. 29: 77-103.

Chambers, I., Colby, D., Robertson, M., Nichols, J., Lee, S., Tweedie, S., and Smith, A. 2003. Functional expression cloning of Nanog, a pluripotency sustaining factor in embryonic stem cells. Cell 113: 643-655.

Chen, Z.F., Paquette, A.J., and Anderson, D.J. 1998. NRSF/REST is required in vivo for repression of multiple neuronal target genes during embryogenesis. Nat. Genet. 20: 136-142.

Cheong, A., Bingham, A.J., Li, J., Kumar, B., Sukumar, P., Munsch, C., Buckley, N.J., Neylon, C.B., Porter, K.E., Beech, D.J., and Wood, I.C. 2005. Downregulated REST transcription factor is a switch enabling critical potassium channel expression and cell proliferation. Mol. Cell 20: 45-52.

Chong, J.A., Tapia-Ramirez, J., Kim, S., Toledo-Aral, J.J., Zheng, Y., Boutros, M.C., Altshuller, Y.M., Frohman, M.A., Kraner, S.D., and Mandel, G. 1995. REST: A mammalian silencer protein that restricts sodium channel gene expression to neurons. Cell 80: 949-957.

Conaco, C., Otto, S., Han, J.J., and Mandel, G. 2006. Reciprocal actions of REST and a microRNA promote neuronal identity. Proc. Natl. Acad. Sci. 103: 2422-2427.

Coulson, J.M. 2005. Transcriptional regulation: Cancer, neurons and the REST. Curr. Biol. 15: R665-R668.

Davis, A.C., Wims, M., Spotts, G.D., Hann, S.R., and Bradley, A 1993. A null c-myc mutation causes lethality before 10.5 days of gestation in homozygotes and reduced fertility in heterozygous female mice. Genes Dev. 7: 671-682.

Dellovade, T., Romer, J.T., Curran, T., and Rubin, L.L. 2006. The hedgehog pathway and neurological disorders. Annu. Rev. Neurosci. 29: 539-563.

Ding, N., Zhou, H., Esteve, P.O., Chin, H.G., Kim, S., Xu, X., Joseph, S.M., Friez, M.J., Schwartz, C.E., Pradhan, S., and Boyer, T.G. 2008. Mediator links epigenetic silencing of neuronal gene expression with $\mathrm{x}$-linked mental retardation. Mol. Cell 31: 347-359.

Eberhart, C.G. and Burger, P.C. 2003. Anaplasia and grading in medulloblastomas. Brain Pathol. 13: 376-385.

Fogarty, M.P., Kessler, J.D., and Wechsler-Reya, R.J. 2005. Morphing into cancer: The role of developmental signaling pathways in brain tumor formation. J. Neurobiol. 64: 458-475.

Formisano, L., Noh, K.M., Miyawaki, T., Mashiko, T., Bennett, M.V., and Zukin, R.S. 2007. Ischemic insults promote epigenetic reprogramming of $\mu$ opioid receptor expression in hippocampal neurons. Proc. Natl. Acad. Sci. 104: 4170-4175.

Fuller, G.N., Su, X., Price, R.E., Cohen, Z.R., Lang, F.F., Sawaya, R., and Majumder, S. 2005. Many human medulloblastoma tumors overexpress repressor element-1 silencing transcription (REST)/neuron-restrictive silencer factor, which can be functionally countered by REST-VP16. Mol. Cancer Ther. 4: 343-349.

Gilbertson, R.J. 2004. Medulloblastoma: Signalling a change in treatment. Lancet Oncol. 5: 209-218.

Griffith, E.C., Cowan, C.W., and Greenberg, M.E. 2001. REST acts through multiple deacetylase complexes. Neuron 31: $339-340$

Guardavaccaro, D., Frescas, D., Dorrello, N.V., Peschiaroli, A., Multani, A.S., Cardozo, T., Lasorella, A., Iavarone, A., Chang, S., Hernando, E., and Pagano, M. 2008. Control of chromosome stability by the $\beta$-TrCP-REST-Mad2 axis. Nature 452: 365-369.

Higashino, K., Narita, T., Taga, T., Ohta, S., and Takeuchi, Y. 2003. Malignant rhabdoid tumor shows a unique neural differentiation as distinct from neuroblastoma. Cancer Sci. 94: 37-42.

Houbaviy, H.B., Murray, M.F., and Sharp, P.A. 2003. Embryonic stem cell-specific microRNAs. Dev. Cell 5: 351-358.

Hsieh, J. and Gage, F.H. 2005. Chromatin remodeling in neural development and plasticity. Curr. Opin. Cell. Biol. 17: 664-671.

Immaneni, A., Lawinger, P., Zhao, Z., Lu, W., Rastelli, L., Morris, J.H., and Majumder, S. 2000. REST-VP16 activates multiple neuronal differentiation genes in human NT2 cells. Nucleic Acids Res. 28: 3403-3410.

Jaenisch, R. and Young, R. 2008. Stem cells, the molecular circuitry of pluripotency and nuclear reprogramming. Cell 132: 567-582.

Jepsen, K., Hermanson, O., Onami, T.M., Gleiberman, A.S., Lunyak, V., McEvilly, R.J., Kurokawa, R., Kumar, V., Liu, F., Seto, E., et al. 2000. Combinatorial roles of the nuclear receptor corepressor in transcription and development. Cell 102: 753-763.

Johnson, D.S., Mortazavi, A., Myers, R.M., and Wold, B. 2007. Genome-wide mapping of in vivo protein-DNA interactions. Science 316: 1497-1502.

Johnson, R., Teh, C.H., Kunarso, G., Wong, K.Y., Srinivasan, G., Cooper, M.L., Volta, M., Chan, S.S., Lipovich, L., Pollard, S.M., et al. 2008. REST regulates distinct transcriptional networks in embryonic and neural stem cells. PLoS Biol. 6: e256.

Kenney, A.M., Widlund, H.R., and Rowitch, D.H. 2004. Hedgehog and PI-3 kinase signaling converge on Nmyc1 to promote cell cycle progression in cerebellar neuronal precursors. Development 131: 217-228.

Kim, C.S., Hwang, C.K., Choi, H.S., Song, K.Y., Law, P.Y., Wei, L.N., and Loh, H.H. 2004. Neuron-restrictive silencer factor (NRSF) functions as a repressor in neuronal cells to regulate the $\mu$ opioid receptor gene. J. Biol. Chem. 279: 46464-46473.

Kim, J., Chu, J., Shen, X., Wang, J., and Orkin, S.H. 2008. An extended transcriptional network for pluripotency of embryonic stem cells. Cell 132: 1049-1061.

Knoepfler, P.S. and Kenney, A.M. 2006. Neural precursor cycling at sonic speed: N-Myc pedals, GSK-3 brakes. Cell Cycle 5: 47-52.

Koenigsberger, C., Chicca II, J.J., Amoureux, M.C., Edelman, G.M., and Jones, F.S. 2000. Differential regulation by multiple promoters of the gene encoding the neuron-restrictive silencer factor. Proc. Natl. Acad. Sci. 97: 2291-2296.

Kuwabara, T., Hsieh, J., Nakashima, K., Taira, K., and Gage, F.H. 2004. A small modulatory dsRNA specifies the fate of adult neural stem cells. Cell 116: 779-793.

Kuwahara, K., Saito, Y., Takano, M., Arai, Y., Yasuno, S., Nakagawa, Y., Takahashi, N., Adachi, Y., Takemura, G., Horie, M., et al. 2003. NRSF regulates the fetal cardiac gene program and maintains normal cardiac structure and function. EMBOJ. 22: 6310-6321.

Lawinger, P., Venugopal, R., Guo, Z.S., Immaneni, A., Sengupta, D., Lu, W., Rastelli, L., Marin Dias Carneiro, A., Levin, V., Fuller, G.N., et al. 2000. The neuronal repressor REST/NRSF is an essential regulator in medulloblastoma cells. Nat. Med. 6: $826-831$.

Lemonde, S., Rogaeva, A., and Albert, P.R. 2004. Cell typedependent recruitment of trichostatin A-sensitive repression of the human 5-HT1A receptor gene. J. Neurochem. 88: 857-868.

Lengner, C.J., Welstead, G.G., and Jaenisch, R. 2008. The pluripotency regulator Oct4: A role in somatic stem cells? Cell Cycle 7: 725-728.

Li, M., Sendtner, M., and Smith, A. 1995. Essential function of LIF receptor in motor neurons. Nature 378: 724-727.

Lie, D.C., Colamarino, S.A., Song, H.J., Desire, L., Mira, H., Consiglio, A., Lein, E.S., Jessberger, S., Lansford, H., Dearie, A.R., and Gage, F.H. 2005. Wnt signalling regulates adult hippocampal neurogenesis. Nature 437: 1370-1375.

Lunyak, V.V. and Rosenfeld, M.G. 2005. No rest for REST: REST/NRSF regulation of neurogenesis. Cell 121: 499-501.

Lunyak, V.V., Burgess, R., Prefontaine, G.G., Nelson, C., Sze, S.H., Chenoweth, J., Schwartz, P., Pevzner, P.A., Glass, C., Mandel, G., and Rosenfeld, M.G. 2002. Corepressor-dependent silencing of chromosomal regions encoding neuronal genes. Science 298: 1747-1752.

Majumder, S. 2006. REST in good times and bad: Roles in tumor suppressor and oncogenic activities. Cell Cycle 5: 1929-1935.

McMahon, A.P. 2000. More surprises in the Hedgehog signaling pathway. Cell 100: 185-188. 
Mitsui, K., Tokuzawa, Y., Itoh, H., Segawa, K., Murakami, M., Takahashi, K., Maruyama, M., Maeda, M., and Yamanaka, S. 2003. The homeoprotein Nanog is required for maintenance of pluripotency in mouse epiblast and ES cells. Cell 113: 631-642.

Nichols, J., Chambers, I., Taga, T., and Smith, A. 2001. Physiological rationale for responsiveness of mouse embryonic stem cells to gp130 cytokines. Development 128: 2333-2339.

Nichols, J., Zevnik, B., Anastassiadis, K., Niwa, H., KleweNebenius, D., Chambers, I., Scholer, H., and Smith, A. 1998. Formation of pluripotent stem cells in the mammalian embryo depends on the POU transcription factor Oct4. Cell 95: 379-391.

Nishihara, S., Tsuda, L., and Ogura, T. 2003. The canonical Wnt pathway directly regulates NRSF/REST expression in chick spinal cord. Biochem. Biophys. Res. Commun. 311: 55-63.

Nishimura, E., Sasaki, K., Maruyama, K., Tsukada, T., and Yamaguchi, K. 1996. Decrease in neuron-restrictive silencer factor (NRSF) mRNA levels during differentiation of cultured neuroblastoma cells. Neurosci. Lett. 211: 101-104.

Otto, S.J., McCorkle, S.R., Hover, J., Conaco, C., Han, J.J., Impey, S., Yochum, G.S., Dunn, J.J., Goodman, R.H., and Mandel, G. 2007. A new binding motif for the transcriptional repressor REST uncovers large gene networks devoted to neuronal functions. J. Neurosci. 27: 6729-6739.

Pan, G. and Thomson, J.A. 2007. Nanog and transcriptional networks in embryonic stem cell pluripotency. Cell Res. 17: 42-49.

Paquette, A.J., Perez, S.E., and Anderson, D.J. 2000. Constitutive expression of the neuron-restrictive silencer factor (NRSF)/REST in differentiating neurons disrupts neuronal gene expression and causes axon pathfinding errors in vivo. Proc. Natl. Acad. Sci. 97: 12318-12323.

Raffel, C. 2004. Medulloblastoma: Molecular genetics and animal models. Neoplasia 6: 310-322.

Romer, J. and Curran, T. 2005. Targeting medulloblastoma: Small-molecule inhibitors of the Sonic Hedgehog pathway as potential cancer therapeutics. Cancer Res. 65: 4975-4978.

Rutka, J.T., Kuo, J.S., Carter, M., Ray, A., Ueda, S., and Mainprize, T.G. 2004. Advances in the treatment of pediatric brain tumors. Expert Rev. Neurother. 4: 879-893.

Schoenherr, C.J. and Anderson, D.J. 1995. The neuron-restrictive silencer factor (NRSF): A coordinate repressor of multiple neuron-specific genes. Science 267: 1360-1363.

Shimojo, M. and Hersh, L.B. 2004. Regulation of the cholinergic gene locus by the repressor element-1 silencing transcription factor/neuron restrictive silencer factor (REST/NRSF). Life Sci. 74: 2213-2225.

Shimojo, M., Paquette, A.J., Anderson, D.J., and Hersh, L.B. 1999. Protein kinase A regulates cholinergic gene expression in PC12 cells: REST4 silences the silencing activity of neuronrestrictive silencer factor/REST. Mol. Cell. Biol. 19: 67886795.

Singh, S.K., Kagalwala, M.N., Parker-Thornburg, J., Adams, H., and Majumder, S. 2008. REST maintains self-renewal and pluripotency of embryonic stem cells. Nature 453: 223-227.

Stewart, C.L., Kaspar, P., Brunet, L.J., Bhatt, H., Gadi, I., Kontgen, F., and Abbondanzo, S.J. 1992. Blastocyst implantation depends on maternal expression of leukaemia inhibitory factor. Nature 359: 76-79.
Su, X., Kameoka, S., Lentz, S., and Majumder, S. 2004. Activation of REST/NRSF target genes in neural stem cells is sufficient to cause neuronal differentiation. Mol. Cell. Biol. 24: 8018-8025. $\mathrm{Su}, \mathrm{X}$., Gopalakrishnan, V., Stearns, D., Aldape, K., Lang, F.F., Fuller, G., Snyder, E., Eberhart, C.G., and Majumder, S. 2006. Abnormal expression of REST/NRSF and Myc in neural stem/progenitor cells causes cerebellar tumors by blocking neuronal differentiation. Mol. Cell. Biol. 26: 1666-1678.

Sun, Y.M., Cooper, M., Finch, S., Lin, H.H., Chen, Z.F., Williams, B.P., and Buckley, N.J. 2008. Rest-mediated regulation of extracellular matrix is crucial for neural development. PLOS ONE 3: e3656.

Tahiliani, M., Mei, P., Fang, R., Leonor, T., Rutenberg, M., Shimizu, F., Li, J., Rao, A., and Shi, Y. 2007. The histone H3K4 demethylase SMCX links REST target genes to Xlinked mental retardation. Nature 447: 601-605.

Takeda, K., Noguchi, K., Shi, W., Tanaka, T., Matsumoto, M., Yoshida, N., Kishimoto, T., and Akira, S. 1997. Targeted disruption of the mouse Stat3 gene leads to early embryonic lethality. Proc. Natl. Acad. Sci. 94: 3801-3804.

Watanabe, Y., Kameoka, S., Gopalakrishnan, V., Aldape, K.D., Pan, Z.Z., Lang, F.F., and Majumder, S. 2004. Conversion of myoblasts to physiologically active neuronal phenotype. Genes Dev. 18: 889-900.

Weissman, A.M. 2008. How much REST is enough? Cancer Cell 13: $381-383$

Westbrook, T.F., Martin, E.S., Schlabach, M.R., Leng, Y., Liang, A.C., Feng, B., Zhao, J.J., Roberts, T.M., Mandel, G., Hannon, G.J., et al. 2005. A genetic screen for candidate tumor suppressors identifies REST. Cell 121: 837-848.

Westbrook, T.F., Hu, G., Ang, X.L., Mulligan, P., Pavlova, N.N., Liang, A., Leng, Y., Maehr, R., Shi, Y., Harper, J.W., and Elledge, S.J. 2008. SCF $\beta$-TRCP controls oncogenic transformation and neural differentiation through REST degradation. Nature 452: 370-374.

Willert, J., Epping, M., Pollack, J.R., Brown, P.O., and Nusse, R. 2002. A transcriptional response to Wnt protein in human embryonic carcinoma cells. BMC Dev. Biol. 2: 8.

Wu, J. and Xie X. 2006. Comparative sequence analysis reveals an intricate network among REST, CREB and miRNA in mediating neuronal gene expression. Genome Biol. 7: R85.

Yamanaka, S. 2008. Induction of pluripotent stem cells from mouse fibroblasts by four transcription factors. Cell Prolif. (suppl. 1) 41: 51-56.

Yu, J. and Thomson, J.A. 2008. Pluripotent stem cell lines. Genes Dev. 22: 1987-1997.

Zuccato, C., Tartari, M., Crotti, A., Goffredo, D., Valenza, M., Conti, L., Cataudella, T., Leavitt, B.R., Hayden, M.R., Timmusk, T., et al. 2003. Huntingtin interacts with REST/ NRSF to modulate the transcription of NRSE-controlled neuronal genes. Nat. Genet. 35: 76-83.

Zuccato, C., Belyaev, N., Conforti, P., Ooi, L., Tartari, M., Papadimou, E., MacDonald, M., Fossale, E., Zeitlin, S., Buckley, N., and Cattaneo, E. 2007. Widespread disruption of repressor element-1 silencing transcription factor/neuronrestrictive silencer factor occupancy at its target genes in Huntington's disease. J. Neurosci. 27: 6972-6983. 


\section{$\$_{\mathrm{CSH}}^{\infty}$ Cold Spring Harbor Symposia SYMPOSIA on Quantitative Biology}

\section{Stemness Is Only a State of the Cell}

M.N. Kagalwala, S.K. Singh and S. Majumder

Cold Spring Harb Symp Quant Biol 2008 73: 227-234 originally published online January 15, 2009 Access the most recent version at doi:10.1101/sqb.2008.73.042

References This article cites 82 articles, 27 of which can be accessed free at: http://symposium.cshlp.org/content/73/227.full.html\#ref-list-1

License

Email Alerting Receive free email alerts when new articles cite this article - sign up in the box at the Service top right corner of the article or click here.

To subscribe to Cold Spring Harbor Symposia on Quantitative Biology go to: http://symposium.cshlp.org/subscriptions 